\title{
Turismo e memórias: práticas e saberes no Assentamento Serra Verde, Barra do Garças - MT
}

\author{
Tourism and memories: practices and knowledge at the Serra Verde settlement, Barra do Garças, \\ Mato Grosso, Brazil
}

\author{
Ana Heloisa Maia ${ }^{1}$ \\ Jenneffer Laura Coelho Gomes ${ }^{2}$
}

\begin{abstract}
Resumo
O presente trabalho tem como objetivo relatar as atividades, práticas e saberes das agricultoras, suas memórias e experiências pessoais a partir da perspectiva de desenvolvimento do turismo no Assentamento Serra Verde, município de Barra do Garças - MT. A metodologia utilizada envolveu a pesquisa bibliográfica e de campo, entrevistas com roteiro semiestruturado a 20 mulheres, análise e interpretação de discursos e observação direta. O potencial de desenvolvimento da atividade turística no Assentamento Serra Verde por meio da análise de representações dos sujeitos e seus papéis na comunidade (suas histórias, diversidade cultural, as memórias, práticas e o saber-fazer) torna-se uma interação fundamental entre o local onde estão inseridos e os indivíduos dessa comunidade. Ao se analisar a percepção das assentadas quanto ao potencial do desenvolvimento do turismo, percebe-se que a produção artesanal e a exploração de atividades de lazer (trilhas e cachoeira) são os principais atrativos aos visitantes, que de forma planejada/orientada/organizada podem gerar uma maior renda às famílias que oferecem esse tipo de serviço. Existem iniciativas importantes no fomento da atividade turística que são estimuladas pelo técnico do assentamento e pelas universidades que atuam no local que envolvem principalmente o trabalho executado pelas mulheres, entretanto, o real desenvolvimento do turismo nas propriedades pesquisadas ainda esbarra em aspectos relacionados à infraestrutura, a questões burocráticas e financeiras, demandando o desenvolvimento de políticas públicas específicas ao fomento da atividade na região.
\end{abstract}

Palavras-chave: Turismo. Mulheres. Planejamento.

\begin{abstract}
This paper aims to report the activities, practices and knowledge of farmer women, their memories and personal experiences based on the perspective of tourism development at the Serra Verde Settlement, Barra do Garças - Mato Grosso State, Brazil. The methodology included bibliographic and field research, direct observation, semi-structured interviews with 20 women, and analysis and interpretation of interviews. The developmental potential of the tourist activity at the Serra Verde Settlement through the analysis of representations of the subjects and their roles in the community (their stories, cultural diversity, memories, practices and know-how) becomes a fundamental interaction between the place where they are located and the individuals of that community. Analyzing the settlers' perception of the potential for tourism development, it is clear that artisanal production and the exploration of leisure activities (trails and waterfalls) are the main attractions for visitors, which conducted in a planned/guided/organized way can generate a higher income for families that offer this type of service. There are important initiatives to promote tourist activity that are stimulated by the settlement's technician and by the universities that work locally, mainly

\footnotetext{
${ }^{1}$ Engenheira agrônoma, Doutora em Agronomia/Sistemas de Produção. Docente da Universidade do Estado de Mato Grosso- UNEMAT Câmpus de Nova Xavantina-MT. E-mail: anaheloisamaia@unemat.br

${ }^{2}$ Graduada em Turismo pela Universidade do Estado de Mato Grosso - UNEMAT Câmpus de Nova Xavantina-MT. Email: jenneffer_gomes@hotmail.com
} 
involving the work performed by women. However, the real development of tourism in the researched settings still confronted by aspects related to infrastructure, bureaucratic and which requires the development of specific public policies to encourage activity in the region.

Keywords: Tourism. Women. Planning.

\section{Introdução}

A agricultura familiar é responsável por grande parte do emprego gerado no campo e o turismo desenvolvido em propriedades familiares permite a diversificação da renda ao oferecer hospedagem, alimentação, cultura e lazer, além da comercialização de produtos locais aos visitantes, favorecendo a integração social e a valorização dos costumes/modo de vida rural.

Este trabalho é um recorte de uma pesquisa mais ampla denominada "Mulheres da terra: trajetória, permanência e empoderamento feminino no Assentamento Serra Verde, Barra do Garças - MT"3. Especificamente no presente trabalho, baseou-se no processo de turistificação do Assentamento Serra Verde, município de Barra do Garças - MT, e a atuação dessas mulheres nesse processo a partir dos produtos ofertados aos visitantes e também os potenciais de realização da atividade turística, objetivando descrever as atividades, práticas e saberes das agricultoras, suas memórias e experiências pessoais a partir da perspectiva de desenvolvimento do turismo no assentamento.

A presente pesquisa visa também descrever as trajetórias das agricultoras e o processo de formação/desenvolvimento da atividade turística dentro do assentamento; identificar as atividades/práticas/saberes que os assentados valorizam e preservam, e propor formas de integrá-las para atrair/aumentar o fluxo turístico no assentamento, bem como verificar a percepção dessas sobre as possibilidades de complementação de renda por meio da atividade turística, com ênfase na agricultura familiar.

Partindo desse pressuposto, entende-se que a incorporação do Assentamento Serra Verde no processo de turistificação está diretamente relacionada às condições históricas estruturais presentes no assentamento, das quais a relação dialética fundamenta a configuração do espaço. Conforme apontado por Knafou (1999), a ação do mercado e sua dinâmica são bases para a turistificação,

\footnotetext{
${ }^{3}$ Coordenadora: Profa. Dra. Ana Heloisa Maia, docente do Curso de Agronomia da Unemat, campus de Nova Xavantina - MT. O projeto é realizado desde 2017, com o objetivo de analisar os aspectos relacionados ao trabalho das mulheres do Assentamento Serra Verde: o lazer, seus projetos de vida e as estratégias utilizadas pelas assentadas para permanência na terra, envolvendo pesquisadores da Universidade do Estado de Mato Grosso - Unemat; Universidade Federal do Estado de Mato Grosso - UFMT, campus de Sinop; Universidade Estadual Paulista Júlio de Mesquita Filho Unesp, campus de Ilha Solteira - SP; e Instituto Nacional de Colonização e Reforma Agrária - Incra, Unidade Avançada do Vale do Araguaia, Barra do Garças - MT.
} 
constituindo produtos e mobilizando pessoas, convertendo recursos naturais em atrativos turísticos, no entanto, "o turismo precisa muito de infraestrutura e serviços, e não somente o meio ecológico com potencial" (KNAFOU, 1999, p. 72).

Segundo Almeida (2010), esse processo acontece quando se encontra uma localidade que sofreu uma intervenção externa, no intuito de prestar serviços a visitantes que tenham a necessidade por tempo determinado de desfrutar do meio ecológico e urbano e que efetivamente são espaços destinados a fluxos turísticos temporários ou permanentes.

Vale ressaltar que no planejamento da atividade turística, o envolvimento de toda a comunidade consegue resgatar os hábitos e costumes enraizados nesta, de forma mais dinâmica, desencadeando entre as famílias a necessidade de manutenção das suas identidades, ressurgindo assim histórias, lembranças, saberes, comidas tradicionais, artes, crenças e valores que passam a ser restituídos ao cotidiano das famílias e estes transformados em atrativos turísticos como característica/marca do local.

Diante do exposto e visando alcançar os objetivos propostos, a primeira etapa do trabalho constituiu-se no levantamento bibliográfico acerca de temas de interesse da pesquisa, por meio de uma análise geral do turismo e da segmentação turismo rural, bem como das particularidades relacionadas ao planejamento da atividade turística. A segunda etapa da pesquisa, realizada em campo, teve o intuito de aprofundar a compreensão sobre o desenvolvimento da atividade turística nos lotes do Assentamento Serra Verde. Para tal se utilizou a análise e interpretação de discursos, com entrevista semiestruturada como instrumento de pesquisa.

\section{Definições e segmentação do turismo}

O turismo é uma atividade mercadológica no mundo, sendo a economia que mais cresce. No Brasil, é quarta economia que mais gera renda. Dessa forma, pode-se dizer que uma das definições de turismo mais aceita é aquela dada pela Organização Mundial do Turismo - OMT (2001, p. 38), que diz que o Turismo é um conjunto de atividades realizadas pelas pessoas durante suas viagens e estadias em lugares diferentes de seu entorno habitual, por um período de tempo consecutivo inferior a um ano, ou no mínimo de período de tempo a vinte quatro horas, tendo em vista lazer, negócios ou outros motivos.

Morgenroth (1929 apud BARRETO, 1995, p. 10) afirma que o turismo é muito mais que o fato de haver o deslocamento de pessoas: 
O turismo é o movimento de pessoas que se afastam temporariamente de sua residência com o objetivo de satisfazer suas necessidades de conhecer outras culturas ou qualquer outro motivo, unicamente como consumidores de culturas e bens econômicos. Já que o turista sempre leva consigo experiências, souvenir e artesanatos.

A autora reforça dizendo que para que o deslocamento de pessoas seja considerado turismo, elas devem se afastar de forma temporária do seu entorno habitual, em busca de outras experiências.

Na cultura contemporânea, o turismo é uma atividade altamente sofisticada, que movimenta bilhões de dólares por ano, envolve uma diversidade de serviços e de pessoas especializadas e atinge centenas de milhares de pessoas em todo o mundo (SENAC, 2005, p. 23).

O envolvimento de diversas pessoas na atividade turística requer um planejamento detalhado para possibilitar a implantação adequada dessa atividade. Dessa forma, a atividade turística terá os impactos negativos minimizados e os impactos positivos maximizados. Além da conscientização da comunidade sobre todos os aspectos do turismo, a qualificação da mão de obra envolvida para desempenhar essa atividade é imprescindível, pois os turistas estão mais exigentes tanto em relação à qualidade do destino, quanto à prestação dos serviços.

A viagem é a forma mais concreta de manifestação de turismo. Porém, o turismo é algo muito mais amplo que o ato de viajar. Atinge outras áreas, como por exemplo, a atividade profissional que exige que as pessoas estejam preparadas para gerenciar e executar os serviços associados à atividade turística. Além do mais, tem a importante função de impulsionar o desenvolvimento econômico (SENAC, 2005, p. 09).

Para Trigo (2002, p. 11), “o turismo faz parte de um universo maior denominado lazer. Entende-se por lazer todas as atividades desenvolvidas fora do sistema produtivo (trabalho), das obrigações sociais, religiosas e familiares”. O lazer nem sempre está relacionado com recreação; também envolve outros fatores como descanso, distração, ócio, leitura, entretenimento, passeios, ou seja, todas as atividades que são feitas no tempo livre de cada indivíduo, atividades que não requerem obrigações. La Torre (1994 apud IGNARA, 2013, p. 15) diz que:

O turismo é um fenômeno social que consiste no deslocamento voluntário e temporário de indivíduo ou grupo de pessoas que, fundamentalmente por motivos de recreação, descanso, cultura ou saúde, saem de seu local de residência habitual para outro, no qual não exercem nenhuma atividade lucrativa nem remunerada, gerando múltiplas inter-relações de importância social, econômica e cultural. 
Para que o deslocamento dos indivíduos seja considerado turismo não pode haver nenhuma atividade lucrativa nem remunerada fora do seu entorno habitual, ou seja, em lugares que o indivíduo não tem o costume de visitar. E os motivos podem ser diversos: lazer, cultural, gastronomia, esportes, aventura.

Para Panosso Netto e Gaeta (2010, p. 46), a relação entre os indivíduos na prática do turismo ocasiona uma gama de posturas, insights, descobertas, frustrações, emoções que serão proporcionadas e embasadas na e pela experiência. Contudo, não se deve confundir experiência com sensação, pois experiência é algo que transforma, é o ato de experimentar. Já a sensação é o ato ter sensibilidade, sentimento.

Sem dúvida, esse é o caminho para vender o turismo como experiência memorável a ser seguido daqui para a frente e lapidado a cada realidade de forma a fortalecer o Destino Brasil e toda a cadeia produtiva do turismo. Panosso Netto e Gaeta (2010, p. 46) dizem que ofertar e trabalhar o turismo dessa maneira é uma forma de alavancá-lo no Brasil. O turismo consome não apenas as atividades, a gastronomia, mas também consome o espaço. Então o espaço precisa ser considerado quando se pensa em implantar o turismo, pois é preciso que o local onde o turismo acontece esteja preservado, conservado.

Antes mesmo de se pensar em qual atividade propor, é necessário pensar na sustentabilidade do espaço. Outro aspecto que necessita de atenção: “o comportamento do consumidor é o processo pelo qual os indivíduos ou grupos selecionam, adquirem, usam produtos, serviços, ideias (SWARBROOKE; HORNER, 2002, p. 27).

É necessário que turistas que buscam uma experiência autêntica estejam dispostos a dispensar algum conforto ou mordomia a fim de que atinjam seus objetivos de experimentar algo novo. "A experiência, que apesar de possuir diferentes graus de intensidade, duração e qualificação, é algo essencial para a articulação profissional e a satisfação pessoal” (NASCIMENTO; MAIA; DIAS, 2012, p. 10).

\section{Espaços, desenvolvimento e o turismo rural}

Dias (2008, p. 61) menciona que o turismo é uma atividade em que os aspectos territoriais, por conter uma importância, não podem ser excluídos de nenhuma análise como um fator social relevante, pois o turismo se desenvolve no espaço, tanto no espaço onde o atrativo se localiza, quanto no percurso para se deslocar até o atrativo e, ainda, também o espaço de origem do turista. Sendo assim, o turista percorre três espaços quando se propõe a fazer uma viagem turística. Pode-se dizer 
que é no espaço que o turismo acontece. Contudo, a atividade turística acontece efetivamente no lugar turístico:

É no lugar turístico que o fenômeno se materializa e sobrepõe suas formas fixas: atrativos turístico, equipamentos e serviços turísticos (meios de hospedagem, serviços, de alimentação, agentes receptivos, guias de turismo, locais e instalações para entretenimento etc.) e infraestrutura de apoio (serviços de comunicações, transportes, segurança etc.). É o lócus da produção e do consumo de produto turístico, que pelas peculiaridades dessa atividade, em alguns momentos ocorrem simultaneamente. (FRATUCCI, 2000, p. 2).

Pelo fato de o turismo acontecer no espaço, é de suma importância a preservação do meio ambiente. Desenvolver metodologias que colaborem para a sustentabilidade dos ambientes envolvidos é uma das alternativas. Contudo, é necessário que a comunidade esteja empenhada para minimizar os aspectos negativos e maximizar os aspectos positivos.

O fato é que a participação da comunidade, como condutora de seus interesses e necessidades e como protagonista da sustentabilidade local, se hoje é desejada, ainda é pouco entendida e também são poucas metodologias que visam ao planejamento e à gestão do uso do solo sendo capazes de incorporar, ativamente, as decisões de cunho político ou técnico. (MARINHO, 2003, p. 115).

“Toda essa preocupação ambiental é relevante, de forma que um empreendimento moderno não pode ser o agressor do meio natural e urbano" (NESPOLO, 2008, p. 27), ou seja, a preocupação de preservação do meio ambiente vem crescendo com o decorrer dos anos. Os turistas estão a cada dia procurando empreendimentos que aderiram à sustentabilidade. Em contrapartida, os destinos turísticos e os empreendimentos estão se adequando a essa nova realidade.

“Aumento da consciência ambiental tem levado à valorização de práticas de lazer relacionadas com o meio ambiente natural, o que permite uma prática turística que utiliza os recursos sem necessidades de maior transformação" (DIAS, 2008, p. 161) como atividades ao ar livre: trilha, observação de pássaros, banho de cachoeira, andar a cavalo, ordenha etc.

O turismo rural é um segmento que vem despontando e um dos motivos é a necessidade dos agricultores em diversificar a sua renda. Segundo o Ministério do Turismo (BRASIL, 2010), turismo rural é o conjunto de atividades turísticas desenvolvidas no ambiente rural, empenhado com a produção agropecuária, agregando valor a produtos e serviços, resgatando e promovendo o patrimônio cultural e natural da comunidade.

O turismo no espaço rural tem como principal característica o envolvimento com o meio ambiente, podendo envolver uma variedade de segmentos, como: turismo ecológico, ecoturismo, 
turismo de aventura, agroturismo, turismo de base comunitária, entre outros, sendo que as atividades desenvolvidas em um segmento interagem com outro segmento, contudo, sempre aliado com a valorização do patrimônio cultural, natural e social.

O Turismo Rural, segmento relativamente novo e em fase de expansão no Brasil, tem seu crescimento explicado por duas razões: a necessidade que o produtor rural tem de diversificar sua fonte de renda e de agregar valor aos seus produtos, e a vontade dos moradores urbanos de reencontrar suas raízes, de conviver com a natureza, com os modos de vida, tradições, costumes e com as formas de produção das populações do interior. (BRASIL, 2015, p. 34).

O agroturismo é um segmento dentro do turismo rural, que complementa a renda familiar sem dispensar as atividades agropecuárias que são sua principal fonte de renda. $\mathrm{O}$ agroturismo tem a função de agregar valor às atividades desempenhadas diariamente no meio rural.

Atividades internas à propriedade, que geram ocupações complementares às atividades agrícolas, as quais continuam a fazer parte do cotidiano da propriedade, em menor ou maior intensidade, devem ser entendidas como parte de um processo de agregação de serviços aos produtos agrícolas e bens não-materiais existentes nas propriedades rurais (paisagem, ar puro etc.), a partir do "tempo livre"e das famílias agrícolas, com eventuais contratações de mão de obra externa. (GRAZIANO DA SILVA et al., 1998, p. 14).

O agroturismo é uma derivação do turismo rural, mas se caracteriza por uma interação mais efetiva entre o turista, a natureza e as atividades agrícolas (TULIK, 1993). De acordo com a autora, o agroturismo é um envolvimento mais concreto entre os turistas e as atividades agrícolas. Além do agroturismo existem as atividades não agrícolas, que contribuem para que a experiência do turista seja mais prazerosa. O turista poderá levar consigo algo que os remete à experiência vivida no âmbito rural, bem como poderá experimentar alimentos e artesanatos que são de origem rural.

Atividades não agrícolas são uma alternativa a mais para a geração de renda para a família. Assim, afirma Fialho e Waquil (2008, p. 2):

Essa atividade permite um melhor aproveitamento do ambiente rural, tornando-se uma alternativa para a manutenção da agricultura familiar, possibilitando agregar valor aos produtos produzidos na propriedade e, por consequência, gerar emprego e renda para as famílias.

Fialho e Waquil (2008) alertam que a implantação do turismo rural pode trazer muitos impactos positivos, contudo, é necessário que mantenha sempre a dinâmica no planejamento. $\mathrm{Na}$ atualidade, os produtos naturais e rurais têm aberto novos mercados e vêm se tornando mais prestigiados, dessa forma, os produtos e serviços da agricultura familiar obtêm uma valorização. O produtor rural não terá que buscar novas fontes de renda na cidade, pois as atividades não agrícolas 
desempenhadas na zona rural poderão suprir suas necessidades e ainda podem se tornar um gerador de renda e empregos como a produção de: artesanatos, doces, bolos, lembrancinhas e muitos outros.

Os turistas do segmento turismo rural, por serem bastante exigentes, prezam pela qualidade do ambiente natural, das unidades habitacionais, do atendimento personalizado, da organização e da diversidade das atividades ofertadas (REJOWSKI, 2003, p. 34). Porém, não se importam com a rusticidade das instalações, uma vez que mobiliário rústico não quer dizer velho ou desgastado.

O que o turista busca é a representatividade da identidade cultural do destino, a autenticidade do meio rural, algo que se diferencie da arquitetura do meio urbano, que transmita paz e tranquilidade, contato com as atividades exercidas no campo. "O espaço rural não pode mais ser pensado apenas como lugar produtor de mercadorias agrárias e ofertador de mão de obra. Além disso, pode oferecer ar, água, turismo, lazer e bens de saúde" (ARAÚJO, 2000, p. 21).

No momento atual, a busca pela sensação de tranquilidade e sossego faz com que a procura por ambientes rurais aumente e, consequentemente, surja mais uma opção de aumento da renda através do uso da propriedade rural para fins turísticos. Assim, o turismo rural surge como uma alternativa geradora de renda e permanência dessas famílias no espaço rural.

Um fato bastante importante é que os turistas que buscam o segmento turismo rural estão dispostos a vivenciar todas as atividades do meio rural. E dessa forma, o turismo de experiência é um excelente meio de agregar os conhecimentos dos agricultores com os dos turistas.

É inegável o poder que o turismo tem no desenvolvimento social e econômico de uma comunidade. A exploração da atividade turística traz inúmeras oportunidades para a comunidade rural, contudo, além dos impactos positivos o turismo também acarreta impactos negativos.

Schneider e Fialho (2000, p. 35) dizem que alguns dos aspetos positivo são:

Como toda atividade, o turismo no meio rural também possui aspectos positivos e negativos. Ele proporciona benefícios, mas também pode causar consequências que trazem problemas para a população local. O turismo rural propicia a valorização do ambiente onde é explorado por sua capacidade de destacar a cultura e a diversidade natural de uma região, proporcionando a conservação e a manutenção do patrimônio histórico, cultural e natural. Pode contribuir, nesse sentido, para reorganização social e econômica local uma vez que oferece benefícios diretos à população local que participa direta ou indiretamente das atividades relacionadas com o turismo.

Fonseca (2003, p. 47) diz que a recente preocupação em valorizar e preservar o patrimônio cultural vem de dois fatores: a globalização e os reforços das identidades locais. A globalização fez com os hábitos e costumes se tornassem homogêneos, ou seja, culturas se misturando umas às outras. Alguns indivíduos e grupos formaram o movimento de resistência, ou seja, começaram a mostrar a importância de valorizar os costumes, hábitos que já estavam quase esquecidos. 
Alocêntrico é uma tipologia de turista, identificada como exploradora, que procura maior contato com a cultura local. Para eles, a experiência turística tem de ser mais autêntica, pois buscam conhecer e vivenciar o cotidiano da comunidade receptora.

De acordo com Cohen (1972 apud DIAS, 2005, p. 83), turistas alocêntricos tiveram grande importância no movimento de resgate do patrimônio cultural, contudo, na atualidade não apenas os turistas alocêntricos consomem esse tipo de segmento. Indivíduos que residem nos grandes centros urbanos que buscam silêncio e sossego também compõem o perfil dos turistas que procuram o segmento do turismo rural.

Segundo Ignarra (2013, p. 76), a atividade turística tem uma enorme importância no desenvolvimento socioeconômico, grande poder de redistribuição espacial de renda e é a única atividade econômica que pode aliar geração de renda e emprego e conservação do meio ambiente. Pois o turismo utiliza o espaço e consome principalmente paisagens. Para que o turismo aconteça, a conservação do meio ambiente é de suma importância.

O contato dos turistas ou visitantes com os nativos de uma localidade colabora para o desenvolvimento cultural de ambos os grupos. A produção artesanal e as manifestações folclóricas podem ser revitalizadas com o interesse dos turistas em conhecê-las (IGNARRA, 2013, p. 76).

A atividade turística também faz com que ocorra um crescimento na geração de empregos, aumento da renda, melhoria na infraestrutura já existente (como saneamento básico, estradas, segurança etc.), qualidade e bem-estar dos moradores. Entretanto, a atividade turística não tem apenas aspetos positivos, possui também aspetos negativos. E se a atividade turística for desenvolvida de forma desordenada pode causar impactos negativos que serão muito maiores do que os impactos positivos.

Segundo Ignarra (2013), o turismo frequentemente é alvo de acusações como grande responsável pela poluição de praias e rios, elevação de preços de imóveis nos locais onde o segmento é consolidado, influencia de forma negativa nos valores das comunidades tradicionais, provoca contingenciamento e congestionamentos, aumenta os roubos, delitos, impactos ambientais e empregos temporários com remunerações bem inferiores. Contudo, esses efeitos negativos podem e devem ser minimizados a partir do planejamento adequado da atividade.

Para que o turismo rural se torne fortalecido é necessário que o poder público, a iniciativa privada e a comunidade receptora invistam nesse segmento. O papel do poder público é facilitar o acesso aos incentivos fiscais e financiamentos de forma desburocratizada para os agricultores familiares. A iniciativa privada pode colaborar com os agricultores ao ofertar cursos 
profissionalizantes, e a comunidade rural, por sua vez, disponibilizar-se a participar dos cursos e se envolver efetivamente no desenvolvimento do turismo.

\section{Planejamento da atividade turística}

Ignarra (2013, p. 2013) conceitua planejamento da seguinte maneira: planejamento consiste na definição dos objetivos, na ordenação dos recursos materiais e humanos, na determinação dos métodos e formas de organização, no estabelecimento das medidas de tempo, quantidade e qualidade, na localização espacial das atividades e outras especificações necessárias. O planejamento é uma importante fase de qualquer processo e da mesma forma é importante para a atividade turística.

Para a Organização Mundial do Turismo - OMT (2001), o planejamento do turismo deve ter como meta indiscutível a criação de benefícios socioeconômico para a sociedade, mas, ao mesmo tempo, deve manter a sustentabilidade do setor turístico através da conservação do meio ambiente e da cultura local. O planejamento deve ser estruturado de modo adequado, enquadrado no tempo e no espaço, e tem de ser aplicado de forma flexível, compreensiva, integrada, ambiental e sustentável, bem como estar baseada na comunidade local e de acordo com a estratégia que seja exequível.

O planejamento da atividade turística chega a ser diferente de outras atividades econômicas pelo fato que envolve uma série de práticas e setores que obrigatoriamente devem ser seguidos, porém, esse planejamento deve ser flexível, pois a atividade turística tem uma variação muito grande. Contudo, é necessário que priorize alguns aspectos, como estar baseado na comunidade local respeitando suas características e peculiaridades, pois com isso beneficia a sustentabilidade do meio ambiente.

As etapas do planejamento turístico que colaboram para que se alcance o objetivo final são: diagnóstico, que é o levantamento de todos os componentes do turismo, tanto dos atrativos e dos potenciais pontos turísticos; logo após é o prognóstico, que é a etapa na qual se definem quais as intervenções devem ser utilizadas e quando; definição das metas ou objetivos que se deseja atingir; definição das maneiras de atingir os objetivos; e implantação das etapas para que se consiga alcançar ou atingir os objetivos propostos.

Uma excelente ferramenta para elaborar um planejamento é a análise SWOT (strengths, weaknesses, opportunities, treats) ou, em português, análise FOFA (força, fraqueza, ameaça, oportunidade). Adequando todo o planejamento nessas quatro características haverá uma compreensão melhor de quais fatores terão prioridade. Conhecendo cada parte do empreendimento as ações serão mais assertivas. A análise SOWT é uma dessas ferramenta que proporciona ao gestor 
ou pequeno empresário o cenário do mercado e de seus concorrentes, fazendo com que ele conheça e estude o seu comportamento, conforme mencionado por Fernandes, Figueiredo e Brasil (2011, p. 5).

\section{Metodologia}

Este estudo caracteriza-se como pesquisa básica, conforme descrito por Silva e Menezes (2001, p. 12): “[...] busca, principalmente, responder perguntas para ampliar o conhecimento que temos do mundo e tudo o que o forma". A partir dessa premissa, tem-se a necessidade de reconhecer/conhecer a realidade das mulheres do assentamento aliando-a à importância do revisitar as memórias, as práticas e o saber-fazer dessas agricultoras como forma de desenvolvimento do turismo, o que permite, por meio desta pesquisa, o compartilhamento dos resultados obtidos para conhecimento e debate sobre essa realidade.

A metodologia científica baseia-se na pesquisa bibliográfica no intuito de coletar maiores informações a respeito do tema e para aproveitar todas as alternativas que já foram analisadas por outros autores. Para Gil (2002, p. 44):

A pesquisa bibliográfica é desenvolvida com base em material já elaborado, constituído principalmente de livros e artigos científicos [...], bem como, aquelas que se propõem à análise das diversas posições acerca de um problema, também costumam ser desenvolvidas quase exclusivamente mediante fontes bibliográficas.

No segundo momento foi realizada a pesquisa de campo, que é a observação dos fatos tal como ocorrem. "Não permite isolar e controlar as variáveis, mas perceber e estudar as relações estabelecidas" (RODRIGUES, 2007, p. 7). A pesquisa de campo se faz necessária para que se tenha uma real clareza dos fatos coletados e para vivenciar todas as narrativas, mesmo de forma lúdica. A coleta de dados foi realizada no Assentamento Serra Verde nos respectivos lotes das agricultoras, tendo como instrumento fundamental na coleta de dados o pesquisador principal. Sob enfoque qualitativo integrado conforme descrito por Godoy (1995, p. 62), onde "um fenômeno pode ser melhor compreendido no contexto em que ocorre e do qual é parte, devendo ser analisado numa perspectiva integrada. O pesquisador vai a campo buscando captar o fenômeno em estudo a partir da perspectiva das pessoas nele envolvidas, considerando todos os pontos de vista relevantes".

O instrumento de pesquisa utilizado foi a entrevista com roteiro semiestruturado. Delgado (2006, p. 20) menciona “dois tipos de entrevistas que produzem fontes orais: o depoimento de história de vida e entrevistas temáticas". Como esta pesquisa busca conhecer a trajetória e o conhecimento adquirido através da vivência de cada uma delas, foi utilizado o "depoimento de história de vida". A 
entrevista foi realizada com 20 mulheres do assentamento. Esse total de mulheres corresponde as que estavam presentes nos lotes no momento da pesquisa e que aceitaram participar. O roteiro de entrevistas foi elaborado visando retratar o histórico de entrada no assentamento (desafios e momentos importantes), como era a vida antes da entrada no assentamento, as principais fontes de renda, o desenvolvimento da atividade turística e seus projetos futuros.

As entrevistas foram realizadas durante as visitas aos lotes/propriedades, buscando empregar uma abordagem que proporcionasse liberdade às mulheres para expor os aspectos inerentes ao tema da pesquisa. Após o trabalho de campo, os dados das entrevistas foram transcritos e analisados. Na transcrição dos relatos/depoimentos, as mulheres foram identificadas somente com a letra M (mulher), seguida do número da entrevista realizada e idade.

Em toda esta análise deve-se considerar que os sujeitos não são plenamente conscientes das estratégias que utilizam, portanto, é necessário um trabalho de análise e interpretação dos discursos, a comparação dos diferentes discursos sobre situações semelhantes e a observação das práticas para melhor alcance dos resultados (MAIA, 2011, p. 4).

Para Orlandi (2009, p. 62),

Os estudos nessa linha de pesquisa possuem sempre um caráter qualitativo interpretativista, que estuda o objeto de investigação em seu contexto natural na tentativa de dar sentido aos fenômenos levando em conta os significados que as pessoas lhe atribuem. Busca-se, no geral, realizar uma "exaustividade vertical" como dispositivo analítico, considerando os objetivos da pesquisa que podem incluir os efeitos de memória, da história, as ideologias, as heterogeneidades, os não ditos e/ou os já ditos, ou seja, o objeto é estudado na sua profundidade/totalidade.

Ressalta-se que como estratégia de interpretação dos depoimentos foram utilizados também os registros das entrevistas com as agricultoras, por meio da captura de falas e memórias citadas durante a execução da pesquisa que identificassem aspectos relacionados ao estudo, de forma a contribuir com a formulação dos resultados apresentados.

\section{Resultados e discussão}

\section{Caracterização do Assentamento Serra Verde}

O Projeto de Assentamento (P.A.) Serra Verde (Figura 1) localiza-se no município de Barra do Garças - MT, a aproximadamente $30 \mathrm{~km}$ do perímetro urbano. O P.A. Serra Verde possui área total de 3000 hectares, divididos em 100 lotes de 17 hectares cada. Conta também com uma área de 
reserva de 600 hectares (indicada em cor azul no mapa), vários cursos d'água e nascentes (INCRA, 2016, p. 1).

\section{FIGURA 1 - MAPA DA ÁREA DO ASSENTAMENTO SERRA VERDE EM BARRA DO GARÇAS - MT}

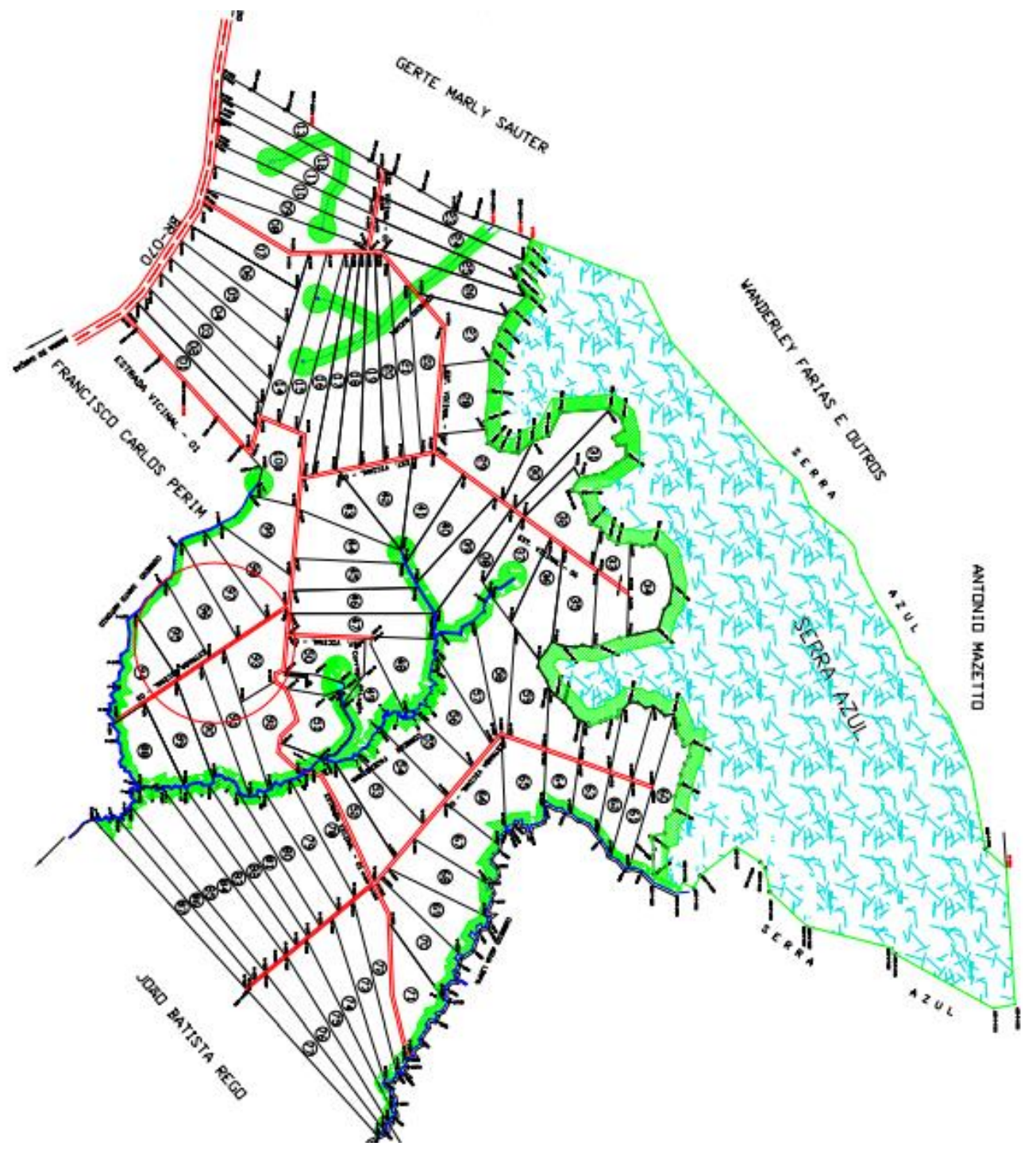

FONTE: INCRA (2018).

O histórico de criação do assentamento deu-se a partir da ocupação das famílias de trabalhadores rurais ao longo da BR-70, próximo à fazenda Serra Verde em 2004. Após vistorias e emissão de laudo de avaliação da improdutividade da área pelo Instituto Nacional de Colonização e Reforma Agrária - Incra, foi publicado no Diário Oficial da União o decreto presidencial de desapropriação por interesse social para fins de reforma agrária ${ }^{4}$ da Fazenda Serra Verde, com imissão

\footnotetext{
${ }^{4}$ A desapropriação por interesse social é aquela que condiciona a propriedade da terra ao cumprimento da sua função social, de acordo com o Estatuto da Terra (Lei $\mathrm{n}^{\circ} 4505$, de 30 de novembro de 1964), verificada na forma prevista dessa
} 
de posse em 2007. No entanto, o expropriado solicitou à Justiça Federal a reintegração de posse do imóvel e por isso apenas em 2009 houve a homologação definitiva do acordo entre Incra e o expropriante, havendo autorização da criação do assentamento e entrada definitiva das famílias na área (OLIVEIRA et al., 2018, p. 3). A partir daquele ano iniciou-se a demarcação das áreas e sorteios dos lotes aos beneficiários, concomitante à liberação dos créditos iniciais pelo Incra para início das atividades produtivas e de infraestrutura nos lotes.

Os cultivos agrícolas principais no assentamento são: abacaxi, banana, hortaliças e mandioca, além da diversidade de espécies nativas, como baru, pequi, caju e mangaba, que são aproveitadas para a venda in natura e processamento artesanal. Na pecuária predomina a criação de bovinos (produção de leite e derivados), aves, suínos e peixes para autoconsumo e comercialização em feiras, além do comércio no próprio assentamento (VITORIANO, 2018, p. 12).

\section{Caracterização das mulheres e das famílias}

Todas as mulheres entrevistadas (20) são de origem rural com experiência anterior na atividade agropecuária, com mínimo de 20 anos na atividade. A faixa etária encontra-se entre 35-60 anos e a maioria (15) possui baixa escolaridade; estudaram no máximo até a $4^{\text {a }}$ série (atual $5^{\circ}$ ano). As famílias possuem em média de 2 a 4 membros, tendo como principais moradores o casal.

A maioria dos filhos(as) das mulheres entrevistadas estuda e/ou trabalha fora do assentamento, principalmente no município de Barra do Garça. A faixa etária dos filhos é em média entre 15 e 29 anos, sendo que em 17 lotes esses alcançaram a maioridade e apenas em um lote foi identificado que mesmo o filho tendo a maioridade ainda mora com a mãe, sendo responsável por atividades diárias do lote, incluindo o turismo rural, que é principal fonte de renda dessa propriedade, o que também demonstra o interesse pela sucessão e continuidade das atividades no lote.

Em relação ao trabalho externo à propriedade, 17 entrevistadas mencionaram exercê-lo esporadicamente; este é reservado principalmente aos homens, que saem da propriedade para trabalhar fora em atividades relacionadas à agropecuária (tratorista e limpeza de áreas) e na área urbana (pedreiro e motorista). Como principais fontes de renda das famílias encontra-se a aposentadoria, trabalho externo, mandioca, derivados (leite e cana-de-açúcar), frutíferas diversas (abacaxi, banana, baru, pequi, caju e mangaba), artesanato e turismo.

lei quando simultaneamente favorece o bem-estar dos que nela vivem, mantém níveis satisfatórios de produtividade, assegura a conservação dos recursos naturais e observa as disposições legais que regulam as justas relações de trabalho (BRASIL, 1964). 


\section{Relatos e memórias da entrada no assentamento}

Menegat (2008) relata que refletir sobre as mulheres assentadas, que ao longo de suas histórias de vida passaram por um processo de migração em busca da terra, é reconhecer que a formação de sua identidade encontra-se repleta de elementos voltados às lembranças das lutas passadas, às experiências vivenciadas e às tradições históricas e culturais que constituíram suas vidas.

Os desafios enfrentados e os momentos vivenciados revelam uma trajetória de luta pela terra desde a decisão de saída de casa (área rural ou urbana), o conflito fundiário e o sonho conquistado que se deu com a entrada no assentamento.

Todas as entrevistadas (20) mencionaram o processo de migração de áreas rurais ao centro urbano em cidades da região como Barra do Garças (MT), Aragarças (GO), Bom Jardim de Goiás (GO) e General Carneiro (MT), cuja trajetória foi marcada pelo assalariamento rural ou urbano e luta pela posse da terra.

Eu e meu marido viemos de Barra [do Garças] mesmo, mas sempre trabalhamos em fazenda, daí viemos pra cidade para ficar mais fácil para os filhos estudar ... era longe e ficava muito cansativo pra eles. Resolvemos acampar na BR, porque queríamos a nossa terra. Muitos passavam e nos chamavam de "vagabundos", buzinavam... Não foi nada fácil, faltava de tudo e quando conseguimos a terra foi uma grande alegria. Foram anos no barraco na beira da estrada e agora temos aqui nosso lar... Nosso canto. (M17, 48 anos).

Saímos do Goiás para vir pra Barra [do Garças]. Lá a gente morava em fazenda. Chegamos aqui na Barra do Garças acabamos trabalhando na cidade; eu fazia faxina e meu marido trabalhava de pedreiro. Quando ficamos sabendo do acampamento, fomos sem pensar muito pra beira da estrada. Era nosso sonho ter uma terra que pudesse ser da gente. Foram 5 anos debaixo da lona na BR e depois que entramos na terra foi mais um ano até a gente começar a construir a casa já no lote certo da gente. (M12, 45 anos).

Quando eu resolvi acampar na beira da estrada, minha vida inteira eu trabalhei pros outros, em fazenda... Queria um pedaço de terra pra mim... Eu sonhei com isso... E pra mim isso aqui é mais que uma realização, é a minha vida. (M6, 68 anos).

Pelos depoimentos das entrevistadas percebe-se que foram muitos os desafios enfrentados para a conquista da terra, que vão desde a saída da cidade de origem ao acampamento e, por fim, ao lote no assentamento. Foi um longo período de resistência para a realização desse sonho de ter uma terra para trabalhar e gerenciar. 
Resultados semelhantes foram encontrados por Alves (2006), que ao analisar o processo de conquista da terra por agricultores do município de Araponga na Zona da Mata mineira desde o ano de 1979 verificou que esse processo constitui a (re)construção da identidade dos agricultores e faz parte da memória e história desse grupo, sendo também uma busca pela liberdade e autonomia de gerenciamento de algo próprio que tanto sonharam.

Silva et al. (2017) e Vitoriano (2018), ao estudarem assentamentos rurais no município de Nova Xavantina e o Assentamento Serra Verde em Barra do Garças, revelam que embora a conquista da terra tenha significados diferentes entre os assentados, essa remonta as memórias passadas e o sentimento de pertencimento a um lugar, de sonhos realizados que, por vezes, lhes foram tomados. Para esses autores, ao se analisar a trajetória desses sujeitos, percebe-se que a permanência na propriedade é uma forma de resistência, que remete a diferentes estratégias para permanecer na terra e persistir no sonho que foi realizado com tanta dificuldade.

\section{Desenvolvimento da atividade turística}

Consolidar o turismo como estratégia de desenvolvimento e inclusão social a partir das memórias, práticas/vivências e cotidiano dos assentados ainda é um desafio que precisa ser superado dentro do assentamento.

As mulheres entrevistadas demonstraram grande interesse na recepção de visitantes em seus lotes (Figura 2). Parte delas (14) recebe visitantes esporádicos (a maioria estudantes de ensino superior e técnico, principalmente para conhecerem projetos de pesquisas e extensão ${ }^{5}$ desenvolvidos no local, e no caso específico de acadêmicos do curso de Turismo da Unemat, envolve a criação de um roteiro turístico nas propriedades e o potencial de desenvolvimento da atividade turística no $\operatorname{assentamento}^{6}$ ), cinco (5) já receberam grupo de pessoas que tinham interesse em trilhas, comidas típicas e a vivência no campo e apenas uma (1) recebe turistas.

\footnotetext{
${ }^{5}$ Unidade Demonstrativa - UD de cultivo de maracujazeiro no lote 27 - Projeto de Pesquisa "Desempenho agronômico de cultivares de maracujazeiro no Vale Araguaia - MT", coordenado pelo docente Manoel Euzébio de Souza do curso de Agronomia da Unemat, campus de Nova Xavantina - MT, desde 2017, financiado pelo Conselho Nacional de Desenvolvimento Científico e Tecnológico (CNPq) - Edital Universal n ${ }^{\circ}$ 01/2016, CNPq-Processo n ${ }^{\circ}$ : 405129/2016-5. ${ }^{6}$ Atividade desenvolvida pelas docentes Katia Maria Pacheco dos Santos e Kelli Carvalho de Mello com os acadêmicos do curso de Turismo da Unemat, campus de Nova Xavantina - MT, nas disciplinas de Turismo Rural e Geografia Aplicada ao Turismo I.
} 


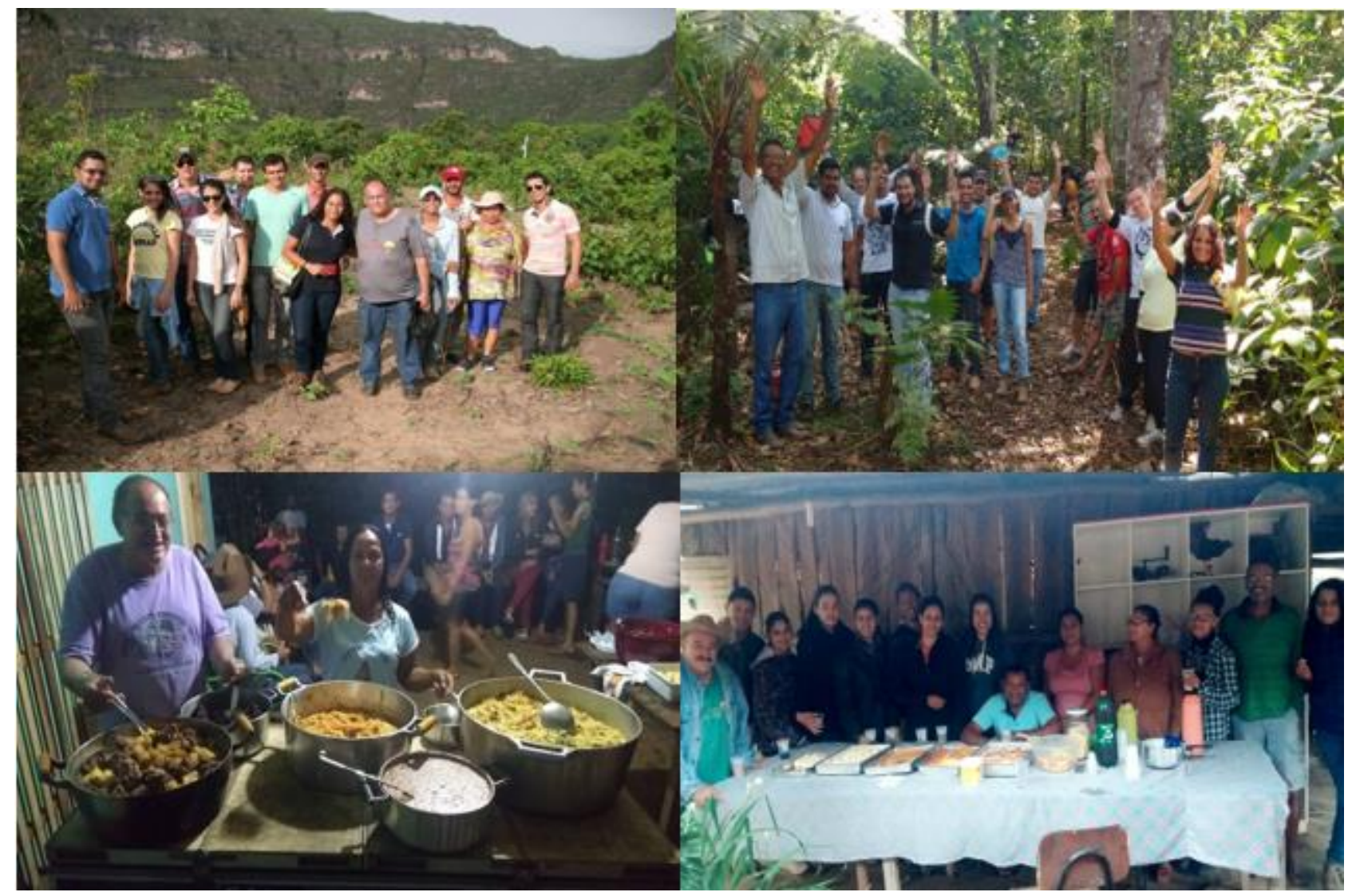

FONTE: Os Autores (2017).

Segundo os relatos orais das assentadas, o incentivo ao desenvolvimento do turismo nas propriedades partiu do técnico de assentamento José Juarez Guimarães Reis, da Unidade Avançada de Barra do Garças, que tem motivado as assentadas a se organizarem nesse sentido, buscando aproximar as universidades (Universidade do Estado de Mato Grosso - Unemat, Universidade do Vale do Araguaia - Univar e Universidade Federal de Mato Grosso - UFMT) e os grupos de interesse na gestão da atividade turística para consolidação do turismo rural no assentamento.

No depoimento a seguir, a assentada relata como recebe turistas em sua propriedade e menciona que os serviços oferecidos são a marca turística, entretanto, relata também que para o desenvolvimento da atividade é preciso melhorar o planejamento e adequação dos serviços ofertados.

As pessoas se interessam em visitar o assentamento, aqui é bonito, tem a serra pra fazer a trilha, tem as cachoeiras e as pessoas querem sentir um pouco o que é viver na roça. Aqui é mais calmo, se quiser pescar pode pescar, se quiser beber leite, comer um queijo, um doce, tem aqui. O que oferecemos é nossa marca; tem coisa que só encontra aqui. Tem gente que vem de longe porque já conhece o que 
oferecemos, mas ainda é preciso adequar o local pra receber os turistas, planejar melhor os serviços que vamos oferecer. (M17, 48 anos).

O referido depoimento vai ao encontro com o mencionado por Medeiros et al. (2015). De acordo com esses autores, os serviços a serem oferecidos correspondem a características que determinam ou representam a marca de um local turisticamente, daí a importância de incluir a participação dos agentes de interesse na atividade turística, já que estão "diretamente ligados às respostas de ações ou reações que serão induzidos [...] e o turismo é uma atividade diretamente dependente de pessoas para acontecer" (MEDEIROS et al., 2015, p. 47).

Quando as entrevistadas que recebem visitantes esporádicos e turistas foram questionadas em relação a "Como surgiu a ideia de trabalhar com a atividade turística?" e "Quais atividades vocês realizam aqui?", elas afirmam que o processo se deu a partir da conversa entre o técnico de assentamento José Juarez e as famílias, que motivadas inicialmente por ele iniciaram o desenvolvimento dessa atividade.

Ressalta-se aqui a importância do papel do agente de ATER - Assistência Técnica e Extensão Rural, mencionada por todas as entrevistadas como fundamental para o estímulo inicial, e do desenvolvimento de outras atividades no lote, verificado também em pesquisa realizada por Vitoriano (2018).

Os resultados da pesquisa realizada por Brito (2017, p. 88) no Assentamento Serra Verde, município de Barra do Garças - MT apontam que:

[...] os assentados são pessoas que se tiverem a devida orientação podem desenvolver um turismo que respeite o ambiente natural do assentamento, adequando as trilhas e capacidade de carga para as cachoeiras, gerando fonte de renda para a comercialização dos produtos ali feitos, e ainda recebendo orientação quanto a conhecimento teórico e prático para o turismo regional.

Relacionando com a presente pesquisa, as mulheres do Assentamento Serra Verde buscam se qualificar e a articulação entre o técnico do assentamento e instituições externas (principalmente universidades) tem permitido a oferta de cursos de capacitação visando incentivar o turismo rural (trilhas e inventário turístico), bem como agregar valor aos produtos nos lotes (boas práticas de produção e fabricação), obtendo, assim, um destino diferenciado de comercialização (feiras e no próprio assentamento), além de servir como atrativo para o recebimento de visitantes de outras localidades.

De acordo com as informações obtidas foi verificado que parte das mulheres (03) já aproveita os recursos naturais existentes na propriedade, como as cachoeiras (Figura 2), que já eram utilizadas 
como atrativo turístico do antigo proprietário da fazenda expropriada (existem duas que são visitadas frequentemente). Outras mulheres foram fomentando diversas atividades (comidas típicas, frutíferas nativas - baru, pequi, araçá, confecção de derivados do leite e da cana-de-açúcar, piscicultura, artesanato etc.) que podem ser utilizadas como atrativos.

\section{FIGURA 3 - CACHOEIRAS NO ASSENTAMENTO SERRA VERDE, BARRA DO GARÇAS - MT}

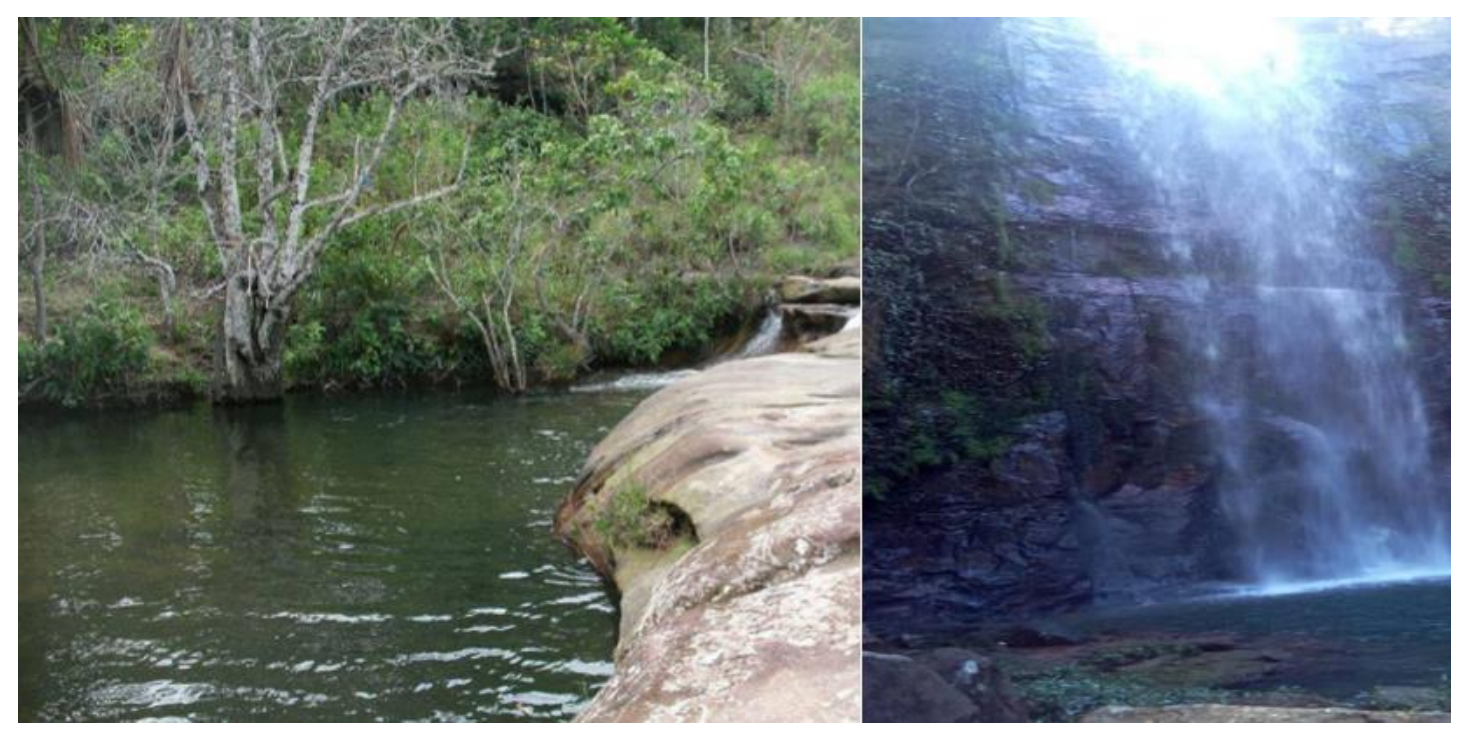

FONTE: Os Autores (2019).

Na propriedade (M18) que recebe turistas, a assentada menciona que os turistas vêm principalmente para saborear a "comida da roça" e conhecer os produtos que são feitos a partir das frutíferas nativas.

Os turistas vêm interessados na comida; quer comer essa comida típica da roça, feita no fogão a lenha, quer experimentar a conserva de pequi minha, a geleia de araçá, a paçoca de baru que minha irmã faz. Tem coisas que já são nossa marca registrada. Quando vamos participar da feira, tem gente que já pergunta: cadê as meninas do Serra Verde? (M18, 48 anos).

Em trabalho realizado por Bezerra e Silva (2018), que ao analisarem e identificarem as potencialidades turísticas do Assentamento Itamarati e Assentamento Itamarati II, em Ponta Porã (MS), concluíram que o turismo é uma grande fonte de emprego e renda para os assentados dessa localidade, e ressaltam que o sucesso da atividade turística não depende somente das belezas naturais do local, mas principalmente de uma prestação de serviços adequada e de qualidade, da hospitalidade de todos os envolvidos. 
O fato de haver esse deslocamento de pessoas para dentro do assentamento, além de permitir a criação de empregos diretos e indiretos, contribui também para "ampliar o universo intelectual do turista, a partir do intercâmbio social e cultural que esta atividade pode possibilitar em seus mais diversos segmentos" (MEDEIROS et al., 2015, p. 44).

Acrescenta-se também a importância da produção artesanal dentro do Assentamento Serra Verde, por ser uma atividade cujas receitas vêm de antepassados distantes, oriunda de uma tradição de servir a famílias e que passa a ser um meio de gerar trabalho e renda às mulheres rurais por meio de suas memórias, práticas e saber-fazer, ao mesmo tempo em que se torna um atrativo a visitantes que tem interesse neste tipo de produto.

Entre os resultados práticos quanto ao desenvolvimento da atividade turística nas propriedades pesquisadas, é perceptível que o público-alvo potencial do assentamento são pesquisadores e universitários em geral. Assim, as experiências obtidas pela hospitalidade e recepção a esses visitantes foram tidas como positivas para as mulheres entrevistadas.

Todo mundo que vem aqui, principalmente os alunos e professores das universidades, ficam encantados pela comida, por nossa simplicidade e pelo jeito que fazemos as coisas. Aquela comida tem outro sabor, no fogão a lenha, o queijo, os doces você não encontra em outro lugar. Porque cada coisa, cada preparo tem nosso jeito de fazer e isso só se aprende vivendo. (M10, 43 anos).

Em relação à infraestrutura das propriedades, acomodações, local para refeições, todas as mulheres entrevistadas mencionaram que não são adequadas e que há uma série de ajustes a serem feitos que envolvem adequações nas acomodações, bem como, boas práticas na fabricação de produtos e confecção dos alimentos, conforme legislação e recomendações da Vigilância Sanitária.

Quanto à realização das melhorias necessárias à infraestrutura e demais adequações, estas esbarram principalmente na falta de recursos financeiros, que é o principal entrave desse processo, mas há ainda a necessidade de especializar-se, contando com tecnologias adequadas à realidade, com o intuito de atingir um público maior no mercado consumidor.

Eu quero fazer meu barracão para processar o baru; onde faço não é adequado. Eu quero poder receber turistas para que eles vejam como é feito todos os produtos do baru... É meu sonho... Mas sou eu e meu marido; a gente não tem dinheiro pra adequar conforme a vigilância pede. (M5, 45 anos). 
Quando questionadas sobre "O que a atividade turística representa(ria) para sua família?”, todas as entrevistadas mencionaram o potencial de desenvolvimento em suas propriedades e que representa(ria) um dinheiro extra para manutenção da família e permanência no lote.

Aqui tem que fazer um pouco de tudo e com o turismo é possível ganharmos o dinheirinho extra pra sobreviver e se manter aqui. (M18, 48 anos).

Para as entrevistadas, dentre as atividades desenvolvidas na propriedade de interesse potencial ao turismo rural destacam-se principalmente: produção de doce de leite, requeijão e melaço de cana-de-açúcar (mencionado por 10 das entrevistadas), trilhas e cachoeiras (8) e comidas típicas feitas no fogão a lenha (3). Uma das assentadas mencionou também que no assentamento há eventos que ocorrem anualmente e acabam sendo atrativos para o turismo, uma vez que são característicos do local, como a feira da agricultura familiar realizada pelo Grupo de Mulheres do Cerrado (Figura 4), pertencente ao assentamento; e o Encontro da Agricultura Familiar, realizado em parceria com docentes da Unemat dos cursos de Agronomia e Turismo.

\section{FIGURA 4 - EXPOSIÇÃO DE PRODUTOS DA AGRICULTURA FAMILIAR CONFECCIONADOS PELO GRUPO} "MULHERES DO CERRADO" DO ASSENTAMENTO SERRA VERDE.

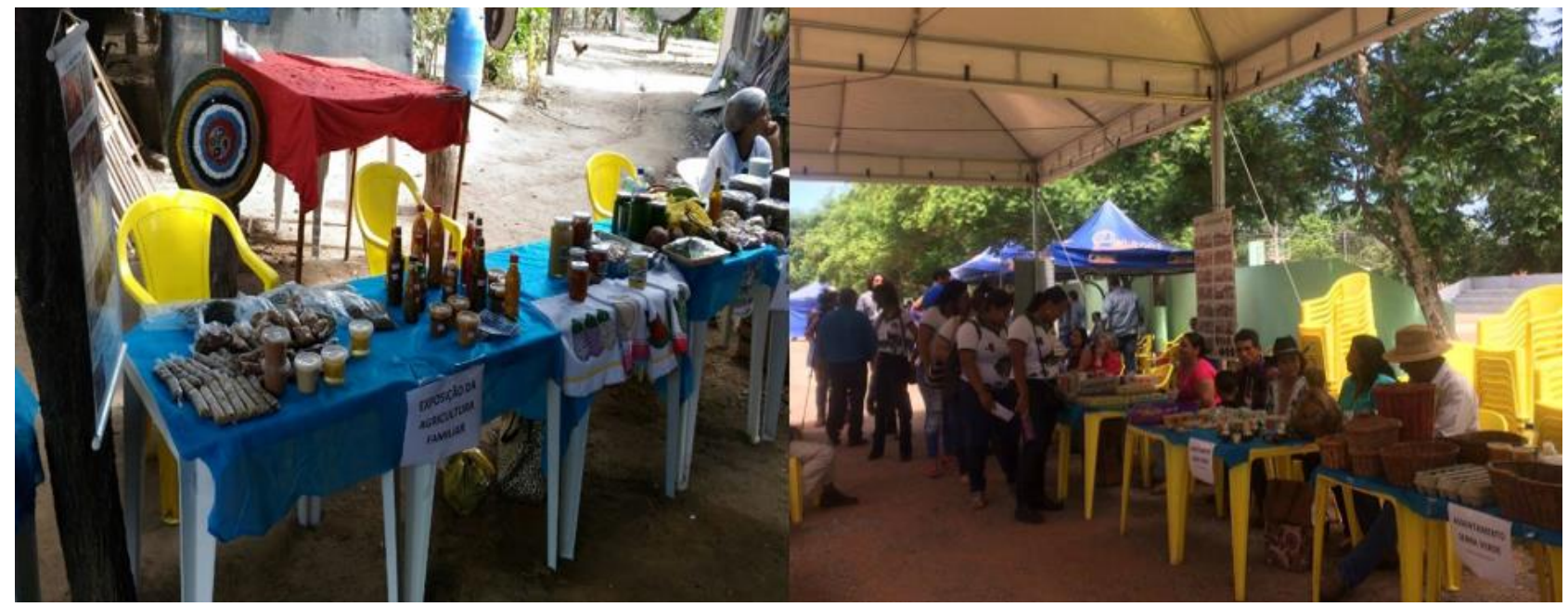

FONTE: Os Autores (2018).

Em relação aos projetos futuros para o desenvolvimento da atividade turística, cinco entrevistas mencionaram a intenção de aquisição de crédito para adequação da infraestrutura da propriedade para recebimento de turistas; as demais não se posicionaram a respeito. 
Dentre as que desejam adquirir crédito (5) para subsidiar a atividade turística na propriedade, foi mencionado por elas que esse projeto é a longo prazo e que ainda esbarram em questões burocráticas, bem como o potencial de pagamento.

\section{Conclusão}

A análise dos resultados do presente trabalho permite identificar que as mulheres do Assentamento Serra Verde são de origem rural, com experiência mínima de 20 anos na atividade agropecuária. A faixa etária das mulheres entrevistadas encontra-se entre 35-60 anos, a maioria com baixa escolaridade (máximo até a $4^{\mathrm{a}}$ série - atual $5^{\circ}$ ano do Ensino Fundamental), embora tenha ocorrido uma evolução da escolaridade quanto aos membros da família quando se compara a escolaridade entre pais e filhos. A média de membros das famílias é entre dois (2) e quatro (4), tendo como principais moradores o casal, responsável pelo desenvolvimento das atividades nos lotes.

As propriedades do assentamento são diversificadas (abacaxi, banana, hortaliças e mandioca, além da diversidade de espécies nativas, como baru, pequi, caju e mangaba, que são aproveitadas para a venda in natura e processamento artesanal), pecuária leiteira, aves, suínos e piscicultura, entretanto, é baixa a renda obtida das atividades que são exploradas. Há ainda o trabalho externo executado predominantemente pelo homem para complemento da renda familiar.

Através dos relatos das mulheres pode-se verificar que suas trajetórias são marcadas predominantemente pela luta pela terra em um processo de migração e assalariamento, rural ou urbano, que levou ao sonho realizado pela entrada no assentamento.

Ao se analisar a percepção das assentadas quanto ao potencial do desenvolvimento do turismo, percebe-se que a produção artesanal e a exploração de atividades de lazer (trilhas e cachoeira) são os principais atrativos aos visitantes, que de forma planejada/orientada/organizada podem gerar uma maior renda às famílias que oferecem esse tipo de serviço.

Existem iniciativas importantes no fomento da atividade turística que são estimuladas pelo técnico do assentamento e pelas universidades que atuam no local em relação principalmente ao trabalho executado pelas mulheres, entretanto, o real desenvolvimento do turismo nas propriedades pesquisadas ainda esbarra em aspectos relacionados à infraestrutura (acomodações inadequadas), burocracia (legislação e vigilância sanitária) e finanças (falta de recursos para maiores investimentos), que demandam o desenvolvimento de políticas públicas específicas ao fomento da atividade na região. 


\section{Referências}

AMATO NETO, J. Redes de cooperação produtiva e clusters regionais. São Paulo: Atlas, 2001.

ARAÚJO, J. G. F. ABC do turismo. Viçosa, MG: Aprenda Fácil, 2000.

BARRETO, M. Manual de iniciação ao estudo de turismo. Campinas: Papirus, 1995.

BACHA, M. L.; STREHLAU, V. I. (2009). Uma tipologia para segmentação de hábitos de viagens das classes populares. Disponível: http://siaiap32.univali.br/seer/index.php/rtva/article/view/300/974. Acesso em: 10 jan. 2017.

BEZERRA, J. S.; SILVA, D. A. O turismo rural como vetor de desenvolvimento local para o assentamento Itamarati em Ponta Porã - MS. Revista Eletrônica da Associação dos Geógrafos Brasileiros, Três Lagoas, v. 28, n. 14, p. 44-67, 2018.

BRASIL. Diretrizes para o desenvolvimento do turismo rural. 2015. Disponível em: http://www.turismo.gov.br/sites/default/turismo/o_ministerio/publicacoes/downloads_ publicacoes/Marketing_Destinos_Turisticos.pdf. Acesso em: 11 jun. 2017.

BRASIL. Ministério do Turismo. Turismo rural: orientações básicas. 2. ed. Brasília: Ministério do Turismo, 2010. 110p.

BRITO, J. E. S. C. M. Plano de ação do Assentamento Serra Verde. Barra do Garças (2017). Disponível em: http://www.mt.gov.br/-/6228444-gdr-apresenta-plano-de-acao-do-assentamentorural-serra-verde. Acesso em: 10 jan. 2018.

DELGADO, L. de A. N. História oral: memória, tempo, identidades. Belo Horizonte: Autêntica, 2006.

DIAS, R. Introdução ao turismo. São Paulo: Atlas, 2005.

DIAS, R. Planejamento do turismo: política e desenvolvimento do turismo no Brasil. São Paulo: Atlas, 2008.

FERNANDES, C.; FIGUEIREDO, R. P.; BRASIL, S. S. Turismo rural em tempos de novas ruralidades (2011). Disponível em: http://www. pasosonline.org /Publicados/p asosoedita/ pasosrep7.pdf. Acesso em: 13 fev. 2017.

FIALHO, M. A. V.; WAQUIL, P. D. Desenvolvimento rural: concepções e referências para a proposição de políticas públicas de desenvolvimento nos territórios rurais. Revista Extensão Rural, Santa Maria, v. 2, n. 15, jan./jun., p. 16-29, 2008.

FONSECA, M. L. Patrimônio, turismo e desenvolvimento local. In: RODRIGUES, A. B. (Org.). Turismo rural: práticas e perspectivas. 2. ed. São Paulo: Contexto, 2003.

FRATUCCI, A. C. Os lugares turísticos: território do fenômeno turístico. GEOgraphia, Niterói, v. 2, n. 4, p. 237-294, 2000. 
GIL, A. C. Como elaborar projetos de pesquisa. 4. ed. São Paulo: Atlas, 2002.

GODOY, A. S. Introdução à pesquisa qualitativa e suas possibilidades. Revista de Administração de Empresas, São Paulo, v. 35, n. 2, p. 57-63, mar./abr., 1995. Disponível em: http:// www. scielo. br/pdf/ rae/v35n2/ a08 v35 n2.pdf. Acesso em: 10 jan. 2017.

GRAZIANO DA SILVA, J.; VILARINHO, C.; DALÈ, P. J. Turismo em áreas naturais: suas possibilidades e limitações no Brasil. In: ALMEIDA, J. A.; RIEDL, M.; FROEHLICH, J. M. (Ed). Turismo rural e desenvolvimento sustentável. Santa Maria: UFSM, 1998. p. 11-47.

IGNARRA, L. R. Fundamentos do turismo. 3. ed. rev. ampl. São Paulo: Cengage Learning; Rio de Janeiro: Senac Rio de Janeiro, 2013. 132p.

INSTITUTO NACIONAL DE COLONIZAÇÃO E REFORMA AGRÁRIA. Dados gerais sobre os assentamentos da SR-18 (2016). Disponível em: www.incra.gov.br. Acesso em: 20 out. 2017.

INSTITUTO NACIONAL DE COLONIZAÇÃO E REFORMA AGRÁRIA. Unidade Avançada do Vale do Araguaia. Mapeamento dos Assentamentos da Região do Vale do Araguaia-MT. Barra do Garças: UAA-Vale do Araguaia, 2018.

KNAFOU, R. Turismo e Território - Por Uma Abordagem Científica do Turismo. In: RODRIGUES, A. A. B. (Org.) Turismo e Geografia - Reflexões Teóricas e Enfoques Regionais. 2. ed. São Paulo: Hucitec, 1999.

MAIA, A. H. Vivências e projetos das jovens rurais: um olhar sob sua condição de mulher na agricultura familiar e a relação com suas estratégias de vida. 99f. 2011. Dissertação (Mestrado em Agronomia) - Faculdade de Engenharia de Ilha Solteira, Universidade Estadual Paulista, Ilha Solteira, 2011.

MARINHO, A. Da aceleração ao pânico de não fazer nada: corpos aventureiros como possibilidade de resistência. In: MARINHO, A.; BRUHNS, H. T. (Orgs.). Turismo, lazer e natureza. Barueri: Manole, 2003. p. 1-28.

MEDEIROS, J. L. de; SIlVA, E. G. da; ARAÚJO, F. S. G.; BARRETO, L. M. T. da S. Comprometimento dos stakeholders no turismo: uma análise do desenvolvimento do Geoturismo no município de Gurjão (Paraíba, Brasil). Turismo \& Sociedade, Curitiba, v. 8, n. 1, p. 38-57, 2015.

MENEGAT, A. S. Mulheres de assentamentos rurais: identidades e trajetórias em construção. Fazendo Gênero 8 - Corpo, Violência e Poder. Florianópolis, 2008.

MORGENROTH (1929). In: BARRETO, M. Manual de iniciação ao estudo de turismo. Campinas: Papirus, 1995.

NASCIMENTO, I.; MAIA, A. F., DIAS, P. O. O. A experiência como produto turístico: a emoção e a sensação do novo e diferente. Turismo: Estudos e Práticas, Mossoró, v. 1, n. 2, p. 142-159, 2012. 
NESPOLO, L. Hotelaria e educação ambiental: reflexões sobre as ações na área de prestação de serviços. 32f. 2008. Monografia (Especialização em Turismo em área Naturais) - Instituto Araguaia de Pós-Graduação, Pesquisa e Extensão, São Paulo, 2008.

OLIVEIRA, G. V.; FERREIRA, P. A.; CORTE, R. T.; GAVLIK, M. Educação agroflorestal no assentamento rural Serra Verde: quatro anos de vivência. Revista Corixo, v. 1, n. 6, p. 112-115, 2018.

ORGANIZAÇÃO MUNDIAL DO TURISMO. Conceptos, definiciones y clasificaciones de las estadísticas de turismo, 2001. Disponível em: https://ajonu.org/2012/10/17/organizacao-mundial-doturismo-omt/. Acesso em: 12 jan. 2017.

ORGANIZAÇÃO MUNDIAL DO TURISMO (2001). IN: SILVEIRA, M. A. Tarlombini da. 112f. 2003 Turismo, políticas do ordenamento territorial e desenvolvimento: um foco no Estado do Paraná no contexto regional. Tese (Doutorado em Geografia) - Universidade do Estado do Paraná, Londrina, 2003.

ORLANDI, E. P. Análise de discurso: princípios \& procedimentos. 8. ed. Campinas: Pontes, 2009.

PANOSSO NETO, A.; ANSARAH, M. G. D. R. Segmentação em turismo: panorama atual. In: PANOSSO NETO, A.; ANSARAH, M. G. D. R. (Ed.). Segmentação do mercado turístico: estudos e perspectivas. Barueri: Manole, 2009. p. 19-44.

PANOSSO NETO, A.; GAETA, C. Turismo de experiência. São Paulo: Senac. 2010.

REJOWSKI, M. Turismo no percurso do tempo. São Paulo: Aleph, 2002.

RODRIGUES, R. M. Pesquisa acadêmica: como facilitar o processo de preparação de suas etapas. São Paulo: Atlas, 2007.

SCHNEIDER, S.; FIALHO, M. A. V. (Orgs.). Atividades não agrícolas e turismo rural no Rio Grande do Sul. Bauru: Edusc, 2000. p. 14-50.

SILVA, T. O.; MAIA, A. H.; SOUZA, M. E.; REBELATTO, B. F.; SOUZA, V. S. Os significados da conquista da terra pelos assentados da região de Nova Xavantina-MT. In: JORNADA CIENTÍFICA DA UNEMAT, 2017. Cáceres. Resumos... Cáceres: Unemat, 2017.

SILVA, E. L.; MENEZES, E. M. Metodologia da pesquisa e elaboração da dissertação. Disponível em: https:// projetos. inf.ufsc.br/ arquivos/Metodologia_de _pesquisa_e_elaboracao_de_teses_e_dissertacoes_4ed.pdf. Acesso em: 10 abr. 2019.

SILVEIRA, M. A. T. da. Turismo, políticas do ordenamento territorial e desenvolvimento: um foco no Estado do Paraná no contexto regional. 112f. 2003. Tese (Doutorado em Geografia) Universidade do Estado do Paraná, Londrina, 2003.

SOLOMON, A. (1996). IN: SWARBROOKE, J.; HORNER, S. O comportamento do consumidor no turismo. São Paulo: Aleph, 2002. 
SWARBROOKE, J.; HORNER, S. O comportamento do consumidor no turismo. São Paulo: Aleph, 2002.

SENAC. Introdução a turismo e hotelaria. Rio de Janeiro: Senac, 2005.

TULIK, O. Recursos naturais e turismo: tendências contemporâneas. In: Turismo e análise, $\mathrm{n}^{\circ} 2$. São Paulo: ECA/USP, 1993.

TRIGO, L. G. Turismo básico. 6. ed. rev. Ampl. São Paulo: Senac,2002.

VITORIANO, C. F. As mulheres do Assentamento Serra Verde, Barra do Garças-MT: trabalho e participação. 38f. 2018. Monografia (Bacharelado em Agronomia) - Faculdade de Ciências Agrárias, Biológicas e Sociais Aplicadas, Universidade do Estado de Mato Grosso, Nova Xavantina, 2018.

Artigo recebido em 20/11/2019. Aceito para publicação em 05/03/2020. 